\title{
Microwave drying of olefins from drill cuttings and analysis of the organic phase recovered during drying operation
}

\author{
Ana C. S. Mota ${ }^{1, *}$, Jéssika M. Santos ${ }^{2}$, Marina S. Pereira ${ }^{1}$, and Carlos H. Ataíde ${ }^{1}$ \\ ${ }^{1}$ Faculty of Chemical Engineering, Federal University of Uberlândia, Av. João Naves de Ávila, 2121, 1K, 38408-100 Uberlândia, MG, \\ Brazil \\ ${ }^{2}$ Department of Chemical Engineering, Federal University of São João Del-Rei, Campus Alto Paraopeba, Ouro Branco, MG, Brazil
}

Received: 16 April 2019 / Accepted: 10 December 2019

\begin{abstract}
The main objective of the present work was to study the influence of different operating conditions in the microwave drying of drill cuttings and an eventual degradation of the condensed liquid collected during this operation. For this, a Central Composite Design (CCD) was used, considering three independent variables at three levels: initial olefin content $(7.5,10$, and $12.5 \% \mathrm{w} / \mathrm{w})$, power $(250,500$, and $750 \mathrm{~W})$, and time $(5,10$, and $15 \mathrm{~min}$ ); the residual olefin content being the response analyzed in the conducted tests without monitoring or control of the cutting's temperature. All three variables studied were statistically significant, presenting a positive or negative effect on residual olefin content. As expected, the initial olefin content had a negative effect on the response. On the other hand, when considering the applied power and the drying time, the effect on decontamination yield was positive. The results showed that cuttings can be decontaminated at lower levels than those required by environmental legislation (offshore drilling), reaching residual olefin mass contents of less than 1\%. Finally, the organic phase of recovered liquids, after the condensation of vapors produced during drying, was analyzed by gas chromatography technique. It was observed greater olefin degradation in the longer and higher power tests, especially in samples of condensed liquid collected inside the microwave oven.
\end{abstract}

\section{Introduction}

Throughout the drilling operation of oil and gas wells, rock fragments, also known as drill cuttings, are continuously removed due to the circulation of drilling fluids in the borehole. In wells of great depth and complexity, synthetic drilling fluids are commonly used in the industry. This specific type of drilling fluid is preferred because it ensures both the mechanical and chemical stability of the well, required to the drilling operation (Caenn et al., 2017; Hermoso et al., 2017; Peysson, 2004).

Drilling fluids are complex mixtures carefully designed and prepared from selected chemicals with the aim of meeting specific drilling well requirements. They are usually composed of colloidal systems with solids and polymers in suspension, and may also present an emulsified phase (Fagundes et al., 2018). In Brazil, until recently, the drilling fluid most used in the petrochemical industry contained a continuous phase composed by $n$-paraffin (organic base) with saturated sodium chloride brine in emulsified form (Petri et al., 2015).

\footnotetext{
* Corresponding author: ana.mota@ufu.br
}

In turn, the mixture composed of fluid and cuttings, which is withdrawn from the drilling column, is directed to a solids control system upon reaching the surface. The solids control system is composed of several types of equipment that promote the separation of fluid and cuttings: vibrating screens, hydrocyclones, and centrifuges. The introduction of the cuttings' dryer in modern systems has the purpose of meeting the environmental regulations for waste disposal. It is critical to achieve a high separation efficiency at each stage. Otherwise, there will be an overload in the subsequent equipment, resulting in a loss of overall separation efficiency. The recovered fluid can be reused, while cuttings obtained at the end of this system still contain a certain amount of fluid adhered to its surface (Petri et al., 2019).

In the coming years, offshore oil exploration on the Brazilian coast will be adjusted to new environmental standards, regarding use, and disposal of drilling fluids. One of the changes implemented by the industry was the gradual replacement of the $n$-paraffin base with internal olefins, which present higher biodegradability (Petri et al., 2015). Another major concern is the reduction of cuttings' organic content, which must be discarded in environment at levels that comply with environmental legislation. 
At the same time, it is important that the treatment method adopted makes the reuse of organic components from recovered condensed liquids possible (Dalmazzone et al., 2004; Santos et al., 2018). In this context, the search for alternative techniques for the drying of cuttings is necessary, since the world tendency is that environmental agencies increase requirements on disposal limits (Santos et al., 2018).

One of the parameters analyzed when evaluating new decontamination technologies for well drilling waste is the possibility to reuse the organic phase of recovered liquids, thus generating great savings in the total costs of the drilling operation (Santos et al., 2018). Techniques such as bioremediation and incineration have proved to be effective in reducing the organic content in drill cuttings. However, such techniques exclude the possibility of reusing this organic phase in the preparation of new emulsions (Ball et al., 2012).

An alternative currently studied on the treatment of drill cuttings to be used after the solids control system is heating by microwave drying. Recent research indicates that this technology is a promising option in the decontamination of drill cuttings (Junior et al., 2017; Pereira et al., 2014, 2015; Petri et al., 2015; Robinson et al., 2009, 2010; Rossi et al., 2017; Santos et al., 2018; Shang et al., 2005, 2006).

In microwave ovens, heat is generated by the transformation of electromagnetic radiation into thermal energy inside the material to be dried, which results in higher energy efficiency and shorter drying times when compared to other traditional thermal desorption techniques. Due to different dielectric properties of constituents in the cuttings, there is selectivity in the sample heating and, as a result, degradation of substances of interest may occur (Mujumdar, 2015).

Although microwave heating may cause the organic compounds' degradation and promote the emulsion breakdown, degradation may be minimized with the control of process variables, like applied power and time. Microwave drying also enables collecting the condensed organic phase during drying process, which can be reused in the formulation of new drilling fluid loads (Santos et al., 2018).

In this context, the objective of the present work was to study the microwave drying in a batch oven as a method of treatment of cuttings contaminated with a synthetic drilling fluid, which organic base is composed of an internal olefin, also evaluating a possible degradation of the organic phase recovered during drying process.

Thus, a Central Composite Design (CCD) was performed for such study, as it is a useful tool that reduces experimental effort and allows a series of relevant discussions. The initial mass content of internal olefin, the applied power and the drying time were defined as independent variables. In turn, the residual mass content of olefin after drying was chosen as the decontamination operation's response.

After executing the CCD tests, to verify if there was chemical modification of organic constituents present in the recovered liquids, samples were collected and analyzed by gas chromatography coupled to mass spectrometer.

\section{Materials and methods}

\subsection{Drill cuttings}

The cuttings used in this work come from oil drilling operations on Brazilian territory (onshore) and were donated by Petrobras. They were initially subjected to isopropyl alcohol (analytical grade) extraction in Soxhlet extractors for the organic phase removal during $48 \mathrm{~h}$. The cuttings were then oven dried at $105^{\circ} \mathrm{C}$ for $24 \mathrm{~h}$ in order to remove water and residual isopropyl alcohol. Subsequently, cuttings were sorted with a 16-mesh sieve and the passing fraction was used in this study.

The characteristic particle size distribution of clean cuttings was obtained using the Malvern's laser diffraction particle analyzer, model Mastersizer 2000. The Fraunhofer approach was employed to analyze the detection of laser light scattering and isopropyl alcohol was used in the dispersion of particles. The Rosin-Rammler-Bennet bi-parametric model was the best fit for the data, presenting a coefficient of determination $\left(R^{2}\right)$ of 0.9981 . The model parameters, $d_{63.2}$ and $n$, were respectively $22.43 \mu \mathrm{m}$ and 0.902 .

The Helium gas pycnometry technique, using the AccuPyc 1331-Micromeritics, was adopted to determine the density of dry and clean drill cuttings: $(2650 \pm 3) \mathrm{kg} \mathrm{m}^{-3}$. The chemical composition of oxides present in clean cuttings was determined by the X-Ray Fluorescence (XRF) technique, using the Bruker S8 Tiger spectrometer. The sample was prepared by pressing and the methodology of analysis was Quant Express. It can be observed that the main elements present in cuttings are silicon, calcium, aluminum, and iron, as shown in Table 1.

The Scanning Electron Microscopy (SEM) technique was performed for the morphological analysis of clean cuttings, using the scanning electron microscope of Carl Zeiss, model EVO MA10. The images obtained can be found in Figure 1.

Both the results obtained by XRF and SEM confirm that the cuttings are clayey sedimentary rocks. Clays are composed mainly of hydrated silicates, as confirmed by the composition presented in Table 1. The images obtained by SEM show more clearly the appearance of the particles' lamellar structure, composed of thin and parallel blades, which is characteristic of clays (Velde, 1995).

\subsection{Drilling fluids}

The synthetic drilling fluid used, Novaplus B, was also donated by Petrobras and is marketed by Schlumberger. This fluid, as previously reported, is an inverse emulsion, being the internal olefin the main constituent of its continuous phase. The experimental result of Carbon-13 Nuclear Magnetic Resonance Spectroscopy showed a mixture of olefin isomers, in which the double bond was placed in different internal chain positions, presenting a number of carbon atoms in the range of $14-20$.

In order to ensure emulsion's stability and suspended solids' mixing, the fluid undergone a vigorous, and continuous mechanical stirring process before being used. The retort method was performed in duplicate to characterize 
Table 1. Chemical composition of clean cuttings.

\begin{tabular}{lcccc}
\hline Oxide & $\mathrm{SiO}_{2}$ & $\mathrm{CaO}$ & $\mathrm{Al}_{2} \mathrm{O}_{3}$ & $\mathrm{Fe}_{2} \mathrm{O}_{3}$ \\
Percentage & 37.19 & 11.01 & 10.87 & 5.66 \\
\hline Oxide & $\mathrm{K}_{2} \mathrm{O}$ & $\mathrm{MgO}$ & $\mathrm{BaO}$ & Others \\
Percentage & 2.84 & 2.56 & 2.34 & 27.53 \\
\hline
\end{tabular}

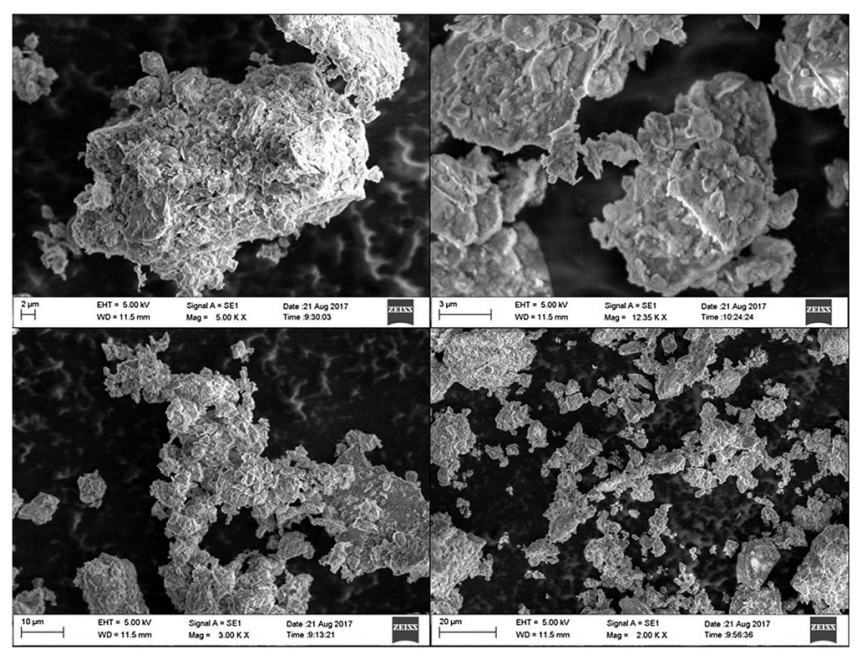

Fig. 1. Images of the clean cuttings obtained by SEM technique.

the fluid, thus obtaining contents of solids, organic and aqueous phase. For this, a $50 \mathrm{~mL}$ FANN Retort Oil and Water Kit was used. In this methodology, a sample of cuttings contaminated with drilling fluid is heated until all organic compounds and water are evaporated. The vapors are condensed and collected in a graduated cylinder, so that the mass concentration of aqueous and organic phases can be calculated by wet mass balance (Pereira et al., 2014). The results obtained for the drilling fluid retort are present in Table 2.

For the gas chromatography of the drilling fluid, an aliquot of the fluid was collected after mechanical agitation, and kept at rest for one week. The supernatant liquid was collected, then filtered on a syringe filter and analyzed on a gas chromatograph coupled to a mass spectrometer, SHIMADZU GCMS-QP2010, with the aid of a $30 \mathrm{~m}$ polymer capillary column of the Rxi-1ms model. Carbon disulfide was the diluent, with an injection of $0.2 \mu \mathrm{L}$. In addition, a heating ramp of $40-250^{\circ} \mathrm{C}$ and a heating rate of $10^{\circ} \mathrm{C} / \mathrm{min}$ was used. The injector and detector temperatures were $300{ }^{\circ} \mathrm{C}$ and $250{ }^{\circ} \mathrm{C}$, respectively (Santos et al., 2014). The chromatogram obtained is shown in Figure 2.

The most expressive peaks in the spectrum are relative to linear chains of 16 and 18 carbons, with double bonds located in different places of the chain. The percentual area relative to peaks showed a ratio of approximately $45 / 55$ between hexadecenes and octadecenes.

\subsection{Contaminated drill cuttings}

Clean cuttings samples were quartered and, by means of wet basis mass balance, the mass of drilling fluid to be
Table 2. Percentual mass content of the olefin-based drilling fluid.

\begin{tabular}{lc}
\hline Organic content (internal olefin) & $32.98 \pm 0.37$ \\
Water content & $31.03 \pm 0.43$ \\
Solids content & $35.99 \pm 0.36$ \\
Organic/water ratio & $52 / 48$ \\
\hline
\end{tabular}

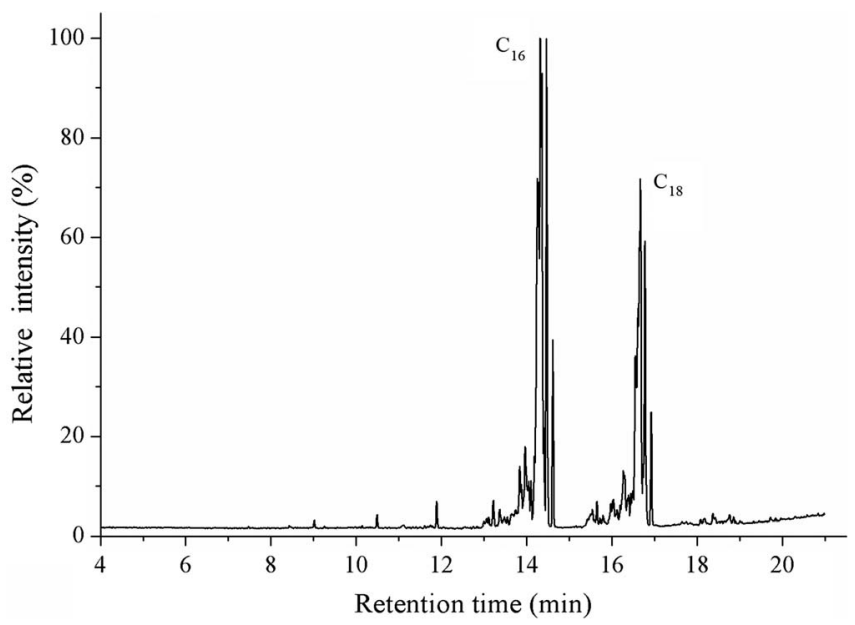

Fig. 2. Chromatogram of the supernatant phase of the drilling fluid.

added to cuttings was determined in order to achieve predetermined olefin contents. At this stage, the drilling fluid also undergone agitation before being added to the cuttings. The mixture was then homogenized and the retort method was performed to confirm if the initial olefin content was sufficiently close to the selected value. The olefin contents used in this work were $7.5,10$, and $12.5 \%$ by mass on a wet basis. The aqueous content in blends is approximately equal to the olefin content due to the drilling fluid composition.

\subsection{Experimental unit and procedure for the drying of cuttings via microwave heating}

Figure 3 is a draft of the experimental unit used in this work, which consists of the following items: (1) Milestone microwave oven, model NEOS-GR, frequency of $2.45 \mathrm{GHz}$ and internal cavity with dimensions of $24 \times 29 \times$ $26.5 \mathrm{~cm}^{3}(\mathrm{~L} \times \mathrm{W} \times \mathrm{H})$; (2) oven control panel; (3) chiller, for cooling the recirculated water in the condenser; (4) vacuum pump, to aid in the removal of vapors from the microwave cavity; (5) refractory porcelain vessel; (6) glass dome; (7) condenser and; (8) separation funnel.

In the microwave drying procedure, a mass of $250 \mathrm{~g}$ of contaminated cuttings was used in each test, which was placed in the porcelain vessel and inserted into the oven in the center of the cavity, as shown in Figure 3. Both time and power applied in each test were set on the oven control panel. The power was selected considering the operating range of the oven, from 10 to $900 \mathrm{~W}$. Subsequently, the 


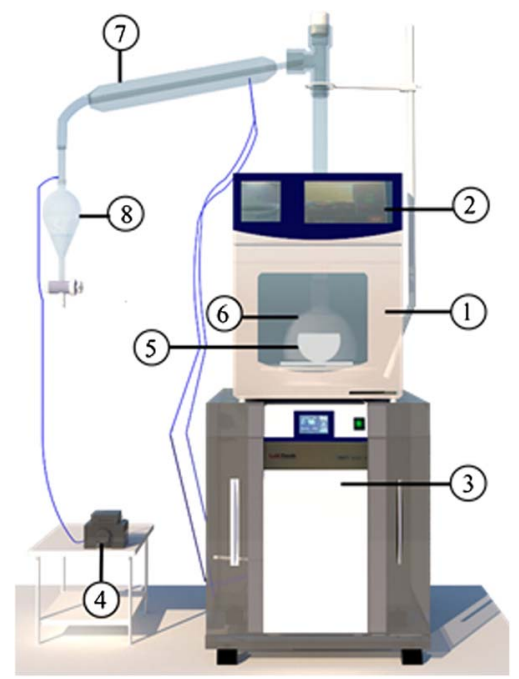

Fig. 3. Microwave unit.

vacuum pump was turned on and the experiment was started. At the end of each test, the retort of the homogenized sample was carried out, allowing the content determination of olefin and residual water present in the cuttings.

It is important to stress that the high heating rate and excessive volume of vapors released during drying tests prevented the temperature measurement with the NEOS-GR infrared sensor.

\subsection{Central composite design}

In the $\mathrm{CCD}$, the independent variables were: initial mass content of olefin (\%), applied power (W), and drying time (min). In turn, the residual mass content of olefin (\%) was the analyzed response. Considering the independent variables and their levels, the set of experiments consisted of 17 trials, of which three are central point replicas. This number of replicas was chosen so that the CCD was orthogonal, being the alpha for orthogonal blocking equal to 1.35. Table 3 shows the CCD matrix, with variables in their coded form.

Table 4 shows the correspondence between coded variables and their respective values in the original scale. The experimental data adjustment was performed using the least squares method, the analysis of variance of multiple regression was based on the coefficient of determination $\left(R^{2}\right)$, and the level of significance selected was $10 \%$. The residual content of olefin was also evaluated according to the Response Surface Methodology (RSM).

\subsection{Analysis of the recovered liquids degradation}

During the drying of cuttings, heating promoted the breakdown of the drilling fluid emulsion, and the subsequent separation of the aqueous phase. These samples were subjected to gentle oven drying, in order to minimize the entrainment of organic phase, until the aqueous fraction was completely removed. Then, the resulting organic phase was subjected to filtration (syringe filter) and analyzed by gas
Table 3. Matrix of the central composite design.

\begin{tabular}{lccc}
\hline Test & Initial content & Power & Time \\
\hline 1 & -1 & -1 & -1 \\
2 & -1 & -1 & +1 \\
3 & -1 & +1 & -1 \\
4 & -1 & +1 & +1 \\
5 & +1 & -1 & -1 \\
6 & +1 & -1 & +1 \\
7 & +1 & +1 & -1 \\
8 & +1 & +1 & +1 \\
9 & -1.35 & 0 & 0 \\
10 & +1.35 & 0 & 0 \\
11 & 0 & -1.35 & 0 \\
12 & 0 & +1.35 & 0 \\
13 & 0 & 0 & -1.35 \\
14 & 0 & 0 & +1.35 \\
15 & 0 & 0 & 0 \\
16 & 0 & 0 & 0 \\
17 & 0 & 0 & 0 \\
\hline
\end{tabular}

Table 4. Correspondence between variables and their coded forms.

\begin{tabular}{lccc}
\hline Level & Content $(\% \mathrm{w} / \mathrm{w})$ & Power $(\mathrm{W})$ & Time $(\mathrm{min})$ \\
\hline-1.35 & 6.63 & 160 & 3.25 \\
-1 & 7.5 & 250 & 5 \\
0 & 10 & 500 & 10 \\
+1 & 12.5 & 750 & 15 \\
+1.35 & 13.38 & 840 & 16.75 \\
\hline
\end{tabular}

chromatography coupled to the mass spectrometer, in order to verify if there was any chemical alteration of the organic phase.

It should be noted that in some of the CCD experiments the collected liquid was composed only of water, which impaired the chemical alteration analysis. This happened mainly in the case of experiments with low drying times.

\section{Results and discussions}

\subsection{Central composite design}

Table 5 shows the results obtained in the CCD experiments. Figure 4 was also designed, relating the test number to the residual content of olefin in cuttings after drying tests.

In experiments 4 and 5 , respectively, the lowest and highest residual contents of olefin were obtained, corresponding to $0.87 \%$ and $12.32 \%$ by mass. Test 4 was performed at a low level of initial contamination $(-1)$ and a high level $(+1)$ of applied power and drying time. The opposite happens in test 5 , performed at a high level $(+1)$ of initial contamination and a low level $(-1)$ of power and time. In this way, it can be confirmed that the initial content exerts a negative influence on the minimization of 
Table 5. Results obtained for the CCD experiments.

\begin{tabular}{lcccc}
\hline Test & $\begin{array}{c}X_{1} \\
\text { (content) }\end{array}$ & $\begin{array}{c}X_{2} \\
\text { (power) }\end{array}$ & $\begin{array}{c}X_{3} \\
\text { (time) }\end{array}$ & $\begin{array}{c}\text { Residual content } \\
(\% \mathrm{w} / \mathrm{w})\end{array}$ \\
\hline 1 & -1 & -1 & -1 & 6.29 \\
2 & -1 & -1 & +1 & 2.79 \\
3 & -1 & +1 & -1 & 4.26 \\
4 & -1 & +1 & +1 & 0.87 \\
5 & +1 & -1 & -1 & 12.32 \\
6 & +1 & -1 & +1 & 11.93 \\
7 & +1 & +1 & -1 & 11.49 \\
8 & +1 & +1 & +1 & 2.17 \\
9 & -1.35 & 0 & 0 & 2.12 \\
10 & +1.35 & 0 & 0 & 11.52 \\
11 & 0 & -1.35 & 0 & 9.07 \\
12 & 0 & +1.35 & 0 & 1.58 \\
13 & 0 & 0 & -1.35 & 9.77 \\
14 & 0 & 0 & +1.35 & 1.15 \\
15 & 0 & 0 & 0 & 4.04 \\
16 & 0 & 0 & 0 & 3.91 \\
17 & 0 & 0 & 0 & 4.12 \\
\hline
\end{tabular}

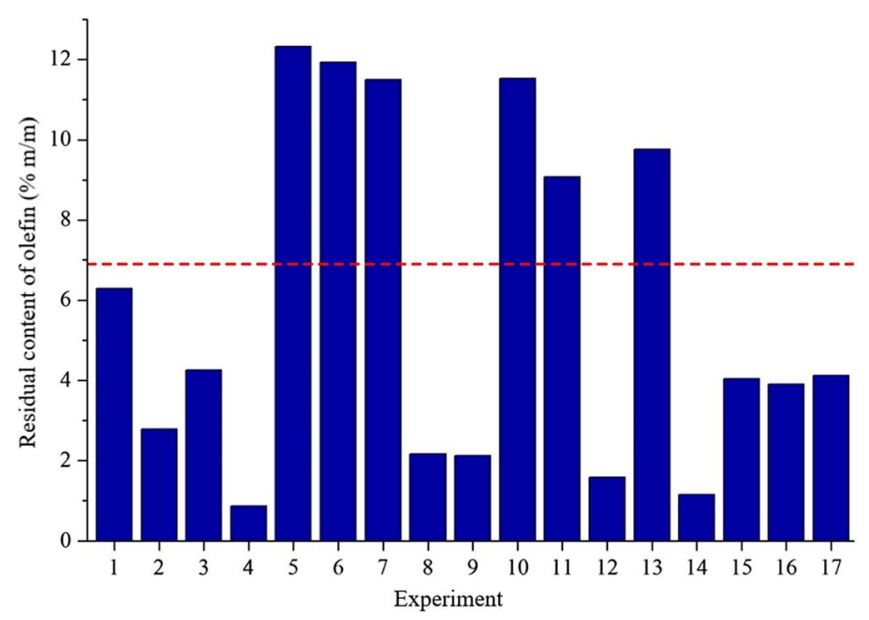

Fig. 4. Residual olefin content of each CCD experiment.

residual olefin content, while power and time favor the decontamination of cuttings. Besides test 4, two other experiments had low olefin residual contents: 12 and 14 . In test 12, a high level $(+1.35)$ of power was used, and in test 14, a high level $(+1.35)$ of drying time was used. The final olefin contents reached were close, for experiment 12 it was $1.58 \%$, and for $14,1.15 \%$.

In six of the 17 tests, residual contents did not comply with current legislation, which establishes a limit of $6.9 \% \mathrm{w} / \mathrm{w}$. The lowest decontamination experiments are those of numbers $5,6,7,10,11$, and 13 . In four of these experiments $(5,6,7$, and 10), the initial content level of the sample was high $(+1$ or +1.35$)$. This confirms the strong negative effect of the initial olefin content on the outcome, as expected.
Despite the considerable number of tests in which the residual contents did not comply with environmental legislation, it is emphasized that the decontamination of samples with high initial levels of olefin is reached when the power or time is increased, as happened in test 8 . Based on results reported in the literature (Pereira et al., 2014; Petri et al., 2015; Rossi et al., 2017; Santos et al., 2014), it is known that, in most cases, an increase of a few minutes in the operating time can result in much more significant decontamination.

The specific energy consumed in drying, associated with the operational cost, is directly related to the variables considered in the CCD. Specific energy is defined as the amount of energy supplied per unit of mass. Once the initial mass of samples inserted in the microwave oven were the same for all experiments, tests with similar values of power and time have the same specific energy. Experiments 1 and 5 , for example, were exposed to the same specific energy $(0.083 \mathrm{kWh} / \mathrm{kg})$. The major difference between the residual olefin contents is due to the initial content, which for test 1 is around $7.5 \%$ and for 5 is $12.5 \%$.

When the initial organic content and specific energy are equivalent for two tests, the corresponding residual contents are close. For example, in experiments 12 and 14, with specific energy of $0.56 \mathrm{kWh} / \mathrm{kg}$, the final residual contents achieved were $1.58 \%$ and $1.15 \%$, respectively. The greatest decontamination occurred precisely for the test 14, in which less power was applied. As discussed in the literature by Pereira et al. (2014) and Santos et al. (2018), lower power values result in lower heating rates, which in turn is associated with lower residual olefin contents. The same behavior can be observed when comparing tests 2 and 3 .

The effect of the significant parameters and the value of the $p$-level of significance are presented in Table 6 . The indexes 1,2 , and 3 are correspondent, respectively, to the initial olefin content, power and drying time.

The model used in RSM is generally a full quadratic equation, which can be written as a second order model as shown in equation (1):

$$
y=\beta_{0}+\sum_{j=1}^{k} \beta_{j} X_{j}+\sum_{j=1}^{k} \beta_{j j} X_{j}^{2}+\sum \sum_{i<j} \beta_{i j} X_{i} X_{j},
$$

in which $y$ is the response (residual content); $\beta_{0}, \beta_{j}, \beta_{j j}$, and $\beta_{i j}$ are regression coefficients for intercept, linear, quadratic, and interaction coefficients, respectively; and $X_{i}$ and $X_{j}$ are coded independent variables.

The value obtained for the coefficient of determination $\left(R^{2}\right)$ was 0.9037 and no trends were observed in the residues distribution, which occurred randomly around the mean, indicating a normal distribution. The residual content was affected by all linear parameters, the quadratic term associated with the initial content, and the power/time combination term. Since the objective is to minimize the residual content, parameters that have negative influence on the objective present positive coefficient values. These are the linear and quadratic parameters associated with the initial content. The response was mainly affected by the linear parameters, which have higher absolute coefficient values. 
Table 6. Adjusted model parameters.

\begin{tabular}{lc}
\hline Coefficient & $p$-level \\
\hline$\beta_{0}=4.93$ & 0.0000 \\
$\beta_{1}=6.25$ & 0.0000 \\
$\beta_{2}=-4.23$ & 0.0008 \\
$\beta_{3}=-4.85$ & 0.0003 \\
$\beta_{11}=2.67$ & 0.0512 \\
$\beta_{22}=\mathrm{NS}$ & $\mathrm{NS}$ \\
$\beta_{33}=\mathrm{NS}$ & $\mathrm{NS}$ \\
$\beta_{12}=\mathrm{NS}$ & $\mathrm{NS}$ \\
$\beta_{13}=\mathrm{NS}$ & $\mathrm{NS}$ \\
$\beta_{23}=-2.21$ & 0.0731 \\
\hline
\end{tabular}

NS, non-significative parameter.

The response surfaces of the reduced model are present in Figure 5. In each graph, the response behavior was plotted against two independent variables in their coded form. Each surface was elaborated by setting the value of the third variable in the center point (level 0).

When analyzing the response surfaces, it was noted that the lowest residual contents are reached when low initial contents and high power levels and drying time are used. This behavior was also verified in previous studies (Pereira et al., 2014; Petri et al., 2015; Santos et al., 2018; Shang et al., 2005).

In summary, the limit value of $6.9 \%$ by mass stipulated by environmental legislation for the disposal of cuttings contaminated with olefin is reached when the initial organic content is at levels equal to or less than $0(10 \% \mathrm{w} / \mathrm{w})$ and, at the same time, the power and the drying time present values equal to or above level $0(500 \mathrm{~W}$ and $10 \mathrm{~min}$, respectively).

\subsection{Analysis of the recovered liquids degradation}

In order to verify if chemical modifications of the organic constituents present in the drilling fluid occurred, liquid samples were collected inside the microwave oven and in the separation funnel after tests. It was not possible to collect samples of all drying tests performed because, sometimes, the operating time was not enough to collect a significant volume of organic phase inside the oven or in the funnel. The results obtained are shown in Table 7.

The analysis of the data presented in Table 7 is qualitative, since in the absence of calibration curves the area of a compound chromatographic peak can be considered linear in relation to its quantity, and the percentage of the linear peak area with its content (Lu et al., 2011).

From Table 7, considering the results obtained for the greater drying times, it was concluded that the organic phase underwent chemical modification during the microwave operation. The modification is observed by the presence of hexyldecanol $\left(\mathrm{C}_{16} \mathrm{H}_{34} \mathrm{O}\right)$ and eicosanol $\left(\mathrm{C}_{20} \mathrm{H}_{42} \mathrm{O}\right)$, whose peaks were not observed in the chromatogram obtained for the olefin-based drilling fluid (Santos et al., 2018).
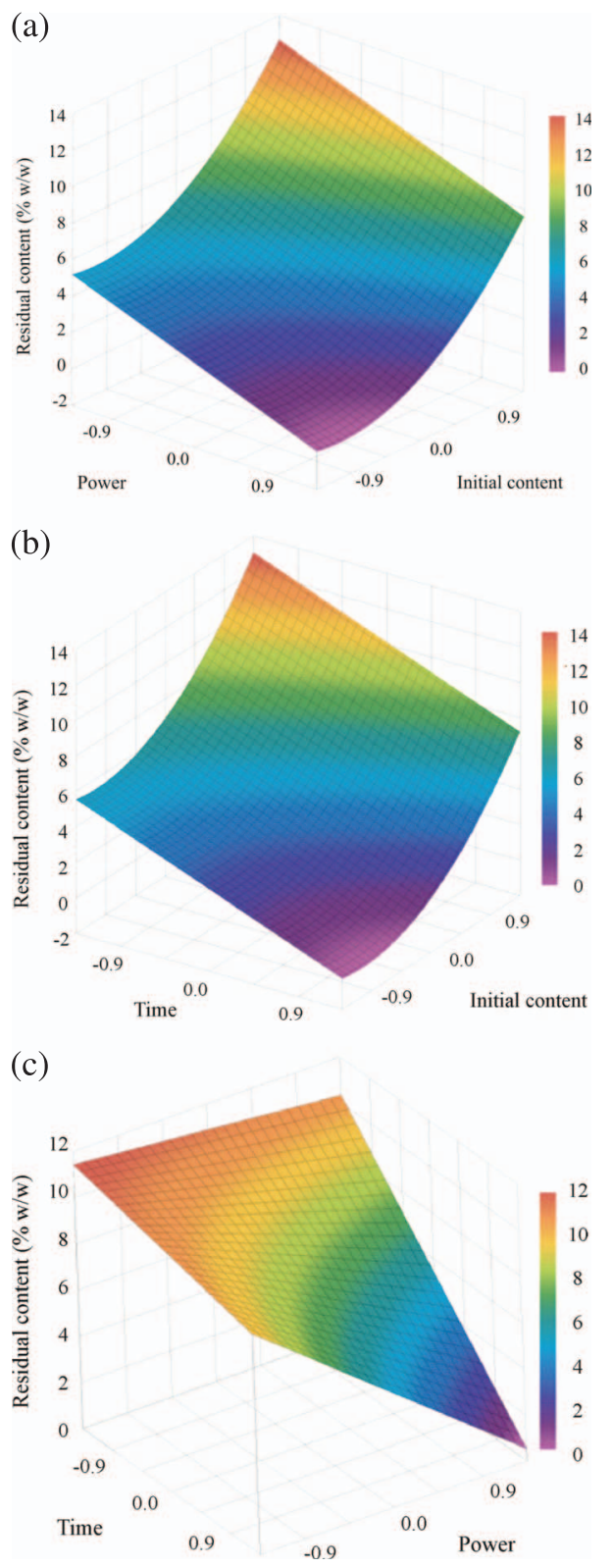

Fig. 5. Response surfaces for the residual olefin content as a function of: (a) power and initial content, (b) initial content and time, and (c) time and power.

The other two hydrocarbons present in the table are the main constituents of the internal olefin: hexadecene $\left(\mathrm{C}_{16} \mathrm{H}_{32}\right)$ and octadecene $\left(\mathrm{C}_{18} \mathrm{H}_{36}\right)$. Santos et al. (2018) demonstrated that the presence of insaturations in the olefinic compounds promotes a higher reactivity of the alkenes when compared to the alkanes, especially with respect to addition reactions. The hydration reaction of alkenes in acidic medium (addition of water to the double bond) may explain the detected compounds, hexyldecanol and eicosanol (Nelson et al., 2009).

Higher temperatures, greater than $500{ }^{\circ} \mathrm{C}$, may have also favored pyrolysis reactions of some olefin components, as observed by Li et al. (2009). The peaks correspondent to 
Table 7. Analysis of the condensed liquid organic phase via GC-MS.

\begin{tabular}{|c|c|c|c|c|c|}
\hline \multirow[t]{2}{*}{ Test } & \multirow[t]{2}{*}{ Collect point } & \multicolumn{4}{|c|}{ Peak area $(\%)$} \\
\hline & & $\mathrm{C}_{16} \mathrm{H}_{32}$ & $\mathrm{C}_{18} \mathrm{H}_{36}$ & $\mathrm{C}_{18} \mathrm{H}_{34} \mathrm{O}$ & $\mathrm{C}_{20} \mathrm{H}_{42} \mathrm{O}$ \\
\hline 1 & - & - & - & - & - \\
\hline \multirow[t]{2}{*}{2} & Funnel & 47.4 & 52.6 & - & - \\
\hline & Plate & 45.5 & 54.5 & - & - \\
\hline \multirow[t]{2}{*}{3} & Funnel & - & - & - & - \\
\hline & Plate & 48.2 & 50.7 & 1.1 & - \\
\hline \multirow[t]{2}{*}{4} & Funnel & 32.1 & 48.5 & 17.2 & 2.2 \\
\hline & Plate & - & 48.8 & 40.7 & 10.5 \\
\hline 5 & - & - & - & - & - \\
\hline \multirow[t]{2}{*}{6} & Funnel & 51.8 & 48.2 & - & - \\
\hline & Plate & 51.3 & 48.7 & - & - \\
\hline 7 & - & - & - & - & - \\
\hline \multirow[t]{2}{*}{8} & Funnel & 43.7 & 50.2 & 5.1 & 1.0 \\
\hline & Plate & 10.2 & 17.1 & 34.4 & 38.3 \\
\hline \multirow[t]{2}{*}{9} & Funnel & 49.7 & 50.3 & - & - \\
\hline & Plate & 49.3 & 47.6 & 3.1 & - \\
\hline \multirow[t]{2}{*}{10} & Funnel & 47.6 & 52.4 & - & - \\
\hline & Plate & 49.6 & 50.4 & - & - \\
\hline \multirow[t]{2}{*}{11} & Funnel & 48.7 & 51.3 & - & - \\
\hline & Plate & 49.6 & 50.4 & - & - \\
\hline \multirow[t]{2}{*}{12} & Funnel & 52.3 & 47.7 & - & - \\
\hline & Plate & 38.9 & 37.3 & 11.6 & 12.2 \\
\hline 13 & - & - & - & - & - \\
\hline \multirow[t]{2}{*}{14} & Funnel & 47.9 & 52.1 & - & - \\
\hline & Plate & 45.8 & 49.5 & 4.7 & - \\
\hline \multirow[t]{2}{*}{15} & Funnel & 51.2 & 48.8 & - & - \\
\hline & Plate & 49.4 & 50.6 & - & - \\
\hline \multirow[t]{2}{*}{16} & Funnel & 47.8 & 52.2 & - & - \\
\hline & Plate & 50.1 & 49.9 & - & - \\
\hline \multirow[t]{2}{*}{17} & Funnel & 52.3 & 47.7 & - & - \\
\hline & Plate & 49.3 & 50.7 & - & - \\
\hline
\end{tabular}

changes in the composition, according to the library used in the analysis of results, may also be directly related to hydrocarbons of chains of $14-16$ carbons. This fact indicates that the carbon chains in the liquid sample may have been broken, since the total number of carbons in the chain, which previously was in the range of 16-18, decreased. Organic compounds of smaller chains of $2-4$ carbons, which would also be observed due to the occurrence of pyrolysis reactions, were not identified in the chromatograms.

The experiment with greatest degradation was number 8 , performed with a sample whose initial olefin content was $12.5 \%$ by mass, power of $750 \mathrm{~W}$ and time of $15 \mathrm{~min}$. Among all experiments, it has the highest specific energy value: $0.75 \mathrm{kWh} / \mathrm{kg}$. It was also noticed that the greatest chemical modifications in the condensed liquid were always observed in the samples collected inside the microwave oven. This fact was already expected, since the condensed liquid inside the oven remained exposed to microwaves and high temperatures throughout the experiment and, therefore, was more susceptible to degradation.

The results initially obtained indicate a limitation of microwaves' usage in the drying of cuttings, because the reuse of olefin is necessary to reduce the overall costs of drilling activity. Despite the considerable degree of degradation found in some experiments, most of the organic phase is collected in the separation funnel. For example, in test 8 , approximately $85 \%$ of the total volume of olefin present in the cuttings was collected in the separation funnel and presented low levels thermal degradation.

Thus, the degradation of organic compounds in the recovered liquid would decrease significantly with the adoption of a more efficient exhaust system. The addition of an inert gas stream would be another option, as it would not only assist in dragging, and removing vapors from the cavity, but would also increase the operation safety once a slightly positive pressure would prevent air from entering the cavity. Another alternative that can be considered is a temperature control system for the sample submitted to drying, which could avoid the chemical modifications observed, according to some results reported by Pereira et al. (2014), Petri et al. (2015), Rossi et al. (2017), and Santos et al. (2018).

\section{Conclusion}

According to the experimental conditions selected and the experimental results obtained, the most relevant conclusions of the present work are:

- Microwave drying is an alternative for the treatment of drill cuttings contaminated with internal olefin, allowing the achievement of lower levels than the ones determined by current environmental legislation. The lowest value obtained for the residual organic content of the drill cuttings was $0.87 \%$ by mass.

- For a given specific energy, lower power values result in lower heating rates, which in turn increase the removal efficiency of the organic phase.

- Acccording to the results obtained with the CCD and the RSM, the initial olefin content negatively influences the decontamination, while the applied power and drying time have a positive influence on the drying operation.

- From the analysis of the data obtained by the gas chromatography technique, the chemical modification of the organic phase present in the recovered liquid was observed during the drying process. However, this degradation can be minimized or even eliminated by the implementation of some simple modifications in the microwave drying unit.

Acknowledgments. The authors are grateful for the technical and financial support of the Coordination for the Improvement of Higher Education Personnel (CAPES), the National Council for Scientific and Technological Development (CNPq), and Petrobras S.A. 


\section{References}

Ball A.S., Stewart R.J., Schliephake K. (2012) A review of the current options for the treatment and safe disposal of drill cuttings, Waste Manag. Res. 30, 5, 457-473. doi: 10.1177/ $0734242 X 11419892$.

Caenn R., Darley H.C.H., Gray G.R. (2017) Chapter 1 Introduction to drilling fluids, in: Composition and Properties of Drilling and Completion Fluids, seventh edition, Gulf Professional Publishing, Boston, pp. 1-34. doi: 10.1016/B9780-12-804751-4.00001-8.

Dalmazzone Ch, Blanchet D., Lamoureux S., Dutrieux E., Durrieu J., Camps R., Galgani F. (2004) Impact of drilling activities in warm sea: Recolonization capacities of seabed, Oil Gas Sci. Technol. - Rev. IFP Energies nouvelles 59, 6, 625-647. doi: 10.2516/ogst:2004045.

Fagundes F.M., Santos N.B.C., Damasceno J.J.R., Arouca F.O. (2018) Study on the stability of a shear-thinning suspension used in oil well drilling, Oil Gas Sci. Technol. - Rev. IFP Energies nouvelles 73, 10. doi: 10.2516/ogst/2018007.

Hermoso J., Martínez-Boza F.J., Gallegos C. (2017) Modeling pressure-viscosity behavior of oil-based drilling fluids, Oil Gas Sci. Technol. - Rev. IFP Energies nouvelles 72, 4, 18. doi: $10.2516 /$ ogst $/ 2017014$.

Junior I.P., Martins A.L., Ataíde C.H., Duarte C.R. (2017) Microwave drying remediation of petroleum-contaminated drill cuttings, J. Environ. Manag. 196, 659-665. doi: 10.1016 / j.jenvman.2017.03.068.

Li D., Zhang Y., Quan X., Zhao Y. (2009) Microwave thermal remediation of crude oil contaminated soil enhanced by carbon fiber, J. Environ. Sci. 21, 9, 1290-1295. doi: 10.1016/S10010742(08)62417-1.

Lu Q., Dong C., Zhang X., Tian H., Yang Y., Zhu X. (2011) Selective fast pyrolysis of biomass impregnated with $\mathrm{ZnCl}_{2}$ to produce furfural: Analytical Py-GC/MS study, J. Anal. Appl. Pyrolysis 90, 2, 204-212. doi: 10.1016/j.jaap.2010.12.007.

Mujumdar A.S. (2015) Handbook of industrial drying, CRC Press, Taylor \& Francis Group, Boca Raton, FL. doi: 10.1080/ 07373937.2014.983704.

Nelson D.J., Brammer C., Li R. (2009) Substituent effects in acid-catalyzed hydration of alkenes, measured under consistent reaction conditions, Tetrahedron Lett. 50, 47, 6454-6456. doi: $10.1016 /$ j.tetlet.2009.08.128.

Pereira M.S., Panisset C.M.Á., Martins A.L., Sá C.H.M., Barrozo M.A.S., Ataíde C.H. (2014) Microwave treatment of drilled cuttings contaminated by synthetic drilling fluid, Sep. Purif. Technol. 124, 68-73. doi: 10.1016/j.seppur.2014.01.011.
Pereira M.S., Santos J.M., Barrozo M.A.S., Ataíde C.H., Martins A.L. (2015) Decontamination of drilled cuttings by microwave drying: Kinetics aspects, Braz. J. Pet. Gas 9, 1, 1-10. doi: 10.5419/bjpg2015-0001.

Petri I.J., Pereira M.S., Santos J.M., Duarte C.R., Ataíde C.H., Panisset C.M.Á. (2015) Microwave remediation of oil well drill cuttings, J. Pet. Sci. Eng. 134, 23-29. doi: 10.1016/j.petrol. 2015.07.022.

Petri I.J., Martins A.L., Duarte C.R., Ataíde C.H. (2019) Development and performance of a continuous industrial microwave dryer for remediation of drill cuttings, J. Pet. Sci. Eng. 176, 362-368. doi: 10.1016/j.petrol.2019.01.075.

Peysson Y. (2004) Solid/liquid dispersions in drilling and production, Oil Gas Sci. Technol. - Rev. IFP Energies nouvelles 59, 1, 11-21. doi: 10.2516/ogst:2004002.

Robinson J.P., Kingman S.W., Snape C.E., Barranco R., Shang H., Bradley M.S.A., Bradshaw S.M. (2009) Remediation of oilcontaminated drill cuttings using continuous microwave heating, Chem. Eng. J. 152, 2-3, 458-463. doi: 10.1016/j.cej.2009.05.008.

Robinson J.P., Kingman S.W., Snape C.E., Bradshaw S.M., Bradley M.S.A., Shang H., Barranco R. (2010) Scale-up and design of a continuous microwave treatment system for the processing of oil-contaminated drill cuttings, Chem. Eng. Res. Des. 88, 2, 146-154. doi: 10.1016/j.cherd.2009.07.011.

Rossi A.S., Faria M.G., Pereira M.S., Ataíde C.H. (2017) Kinetics of microwave heating and drying of drilling fluids and drill cuttings, Dry. Technol. 35, 9, 1130-1140. doi: 10.1080/ 07373937.2016.1233425.

Santos J.M., Pereira M.S., Júnior I.P., Pena M.M.R., Ataíde C. H. (2014) Microwave drying of drilled cuttings in the context of waste disposal and drilling fluid recovery, Energy Technol. 2, 9-10, 832-838. doi: 10.1002/ente.201402053.

Santos J.M., Petri I.J., Mota A.C.S., Morais A.S., Ataíde C.H. (2018) Optimization of the batch decontamination process of drill cuttings by microwave heating, J. Pet. Sci. Eng. 163, 349-358. doi: 10.1016/j.petrol.2018.01.003.

Shang H., Snape C.E., Kingman S.W., Robinson J.P. (2005) Treatment of oil-contaminated drill cuttings by microwave heating in a high-power single-mode cavity, Ind. Eng. Chem. Res. 44, 17, 6837-6844. doi: 10.1021/ie0500772.

Shang H., Snape C.E., Kingman S.W., Robinson J.P. (2006) Microwave treatment of oil-contaminated north sea drill cuttings in a high power multimode cavity, Sep. Purif. Technol. 49, 1, 84-90. doi: 10.1016/j.seppur.2005.08.012.

Velde B. (1995) Composition and mineralogy of clay minerals, Springer, Berlin, Heidelberg, pp. 8-42. doi: 10.1007/978-3-66212648-6 2. 